International Journal of Engineering \& Technology, $7(3.20)(2018) 469-474$
International Journal of Engineering \& Technology
SPC
Website: www.sciencepubco.com/index.php/IJET
Research paper

\title{
Knowledge of Five-Tier Fish Farming
}

\author{
Dr.Punya Lertgrai \\ Associate Professor, Faculty of Education, Nakhon Si Thammarat Rajabhat University. \\ *Corresponding Author Email: punya97lert@gmail.com
}

\begin{abstract}
A study about the knowledge of five-tier fish farming was conducted in order to study:1) the learning process and knowledge about the five-tier fish farming, and 2) the process of developing a five-tier fish farming model using qualitative research. By analysing and synthesising, the researcher tried to develop knowledge and lessons on how to solve farmers' problems. Using knowledge about the nature of the fish, the aim was to develop a fish farming model in the target area. The research found that five-tier fish farming is well suited to lowland conditions when there is a canal nearby and family members can be used. Knowledge about the right management style will enable farmers to live well in their community. By learning, observing, monitoring and investigating phenomena happen and using the obtained knowledge to develop continuously and with academic and government support, farmers can obtain their goals. Educational field trips, listening to new ideas and analysis of talks with knowledgeable people will also be useful. The model obtained in this way will have to be tried out and periodically evaluated with input from the grassroots. Knowledge obtained through small-scale experiments can then be used on a bigger scale in order to expand the results. Small experiments in five-tier fish culture can be used as the learning base for the process of naturally raising fish. The learning process must be self-directed through development and evaluation of knowledge and wisdom. This has to be done by observation, analysis and self-management of various models. The results of any evaluation should be discussed with knowledgeable experts. Then turn back to the development stage and to further trials. Development should be analysed using the Spiral Model to achieve better results and to finally arrive at a form of five-tier fish farming that is suitable to the environment of each area.
\end{abstract}

\section{Introduction}

In today's information society we see continuous and severe social and economic changes. People have to face a multitude of problems in culture and need to adjust to survive. They need to learn new ways to solve new problems; they have to adapt their social status and readiness. Decisions are under pressure; people face limits and suffer from economic oppression. Let's consider the direction ahead. They could try to learn from traditional wisdom and knowledge or from neighbours by using the past experiences or ask for advice from people they trust. Also through exchange of knowledge with people they are close to. The information given however may not be sufficiently clear. Thus discretion is needed, together with the right mental state and common sense. The information may not be complete enough to make a decision; as a consequence the decision may be wrong. By learning from past mistakes, we can avoid this. Through carefully conducting small experiments, checking and double-checking and only then gradually expanding the results we can achieve this. Emphasis should be on traditional wisdom and the natural environment [7].

Socio-economic changes in the community led people to try monoculture farming, mainly shrimp and fish. But this single species farming needs a lot of investment; improving the production process requires new technologies and constant innovation. Modernization of the production process is necessary; this often requires expensive imported materials and equipment.
Both species are expensive to buy and food and chemicals require a high investment. Even though this kind of farming has the possibility of high returns, a small error can cause great damage. There is a great risk of losing one's investment and a high impact on the environment.

The learning process of managing ponds and aquariums can greatly benefit from the following five steps. Use real experiences observed by farmers; check the occurrence of natural phenomena from local sources in the area each month, each season. Take lessons from traditional knowledge from previous generations, focus on using nature as an investment instead of using your budget for expensive imported equipment and technology. Mistakes are always possible, leading to serious losses. Observe the natural biology of aquatic animals. It is a good idea to develop a model that is consistent with the environment of the area [3]. Find a guideline to reduce production costs and risk in various areas. Put various types of fish in the same pond. It is good for the farmer and the environmental system of the community.

Fish pond management should include the process of learning the nature of fish and aquatic animals from natural sources. Create fish ponds and aquariums that are based on natural patterns in the environment. Add fish and fish species that are appropriate to the size of the area, water conditions, give food that corresponds to the natural behaviour. Environmentally-friendly management of space, time and resources is the way to proceed giving the highest economic and environmental returns. There are small ecosystems in the area around the water source of the household that are suitable as a model for the management system. 


\section{Research Methodology}

The researchers used qualitative research in data collection and analysis. To synthesize the lesson learned in wisdom development, social movement of farmers in target areas was studied. The research process was as follows.

\subsection{Research Procedure}

Literature Review for the Research. Research results from various theses, research papers, and related texts were synthesized for the study, the interview guideline and discussion guideline. Studying related literature can help the researcher get an understanding of the way people within the community think and learn. [4]. The process of learning and developing, the process of accepting and developing wisdom by oneself takes place within the community. Learning to think and applying wisdom for development and innovation in an appropriate environment are necessary to create a complex ecosystem in the area of the household.

Data were collected through surveying the area. Social contexts related to natural water sources, fish and marine animals were studied in Chian Yai district. Physical and social characteristics of the community were studied through a non-participant observation and the 360 degree participant method, [11] periodically recording the phenomena and interesting events occurring. Informal interviews with relevant people were conducted to find out more about occurring events or issues. Group discussions to get information on ponds, fish in its natural habitat, farmed fish ponds created in the area, and opinion on fish farming, fish species and aquatic animal were held. (Focus group interviews and focus group discussions) to reveal compete information in diverse dimensions [1].

The researcher has taken lessons learned from the main ideas of academic theories used in research as a guide for the research design on patterns of knowledge development in fish and aquaculture management. The research tools used to conduct the research process can be divided into 2 phases.

Phase 1: Contextual Study and Learning Process

1) Definition of the research area; Wa Yai Village, Sai Maak SubDistrict, Chian Yai District, Nakhon Sri Thammarat Province.

2) Data Collecting: the data were collected by survey, using the following techniques: single interviews, group interviews, ex-post facto approach Interviews, occasionally using historical imagery or traces of existing phenomena [10].

Phase 2: Evaluation and Development. Following steps were taken:

1) In-depth interviews to collect and evaluate data. The CIPP model was used as a guideline for assessing research practice.

2) Implementation of the results of the development process within the group using a Spiral Model, synthesis, and systematic summary [12].

3) Data Analysis: the researcher took the information from the group discussion, then analysed using categories as the concept Theory was analysed with linking factors from existing data of repeatedly occurring phenomena. All the data were analysed again using Focus Group Analysis and summarized in a seminar [13].

\subsection{Data Collection Tools}

The tools used by the researcher were: 360 degree visual observation, individual interviews, group interviews, group discussion or focus group discussion. Focus Group Analysis was focused on data from the various sources. [5].

\subsection{Data Validation}

The researcher has verified the information through triangulation and checking the data from at least three different sources from the four data types. These types are the information source, the information investigation, theory of search and how to find information [1]. This to ensure that the information is as genuine and reliable as possible.

\subsection{Selecting Key Informants}

The researchers studied the target population in order to locate three kinds of informants: farmers who were willing to learn about the management of five-tier fish ponds and aquatic animals and were prepared to develop the knowledge to adapt innovations that suit the conditions; people with experience in water management and scholars in the field of natural fish farming and aquatic ecology. They were located through theoretical sampling.

\subsection{Data Analysis}

1) After Action Review. After one year, the data were collected at the end of the farming cycle, and lessons were learned from postoperative analysis or through After Action Review). After harvesting using the five-tier fish farming, a model was developed using the Technique Appropriate Method [15].

2) Learning by doing (Peddler Model). The researcher gained results from local wisdom about natural phenomena occurring each season, the water system, water sources, species of fish and aquatic animals, and organised them into a system. Starting from a small experiment one should repeat the process to make the learning process more complete. Using Peddler's pedagogical approach, farmers are encouraged to learn and develop their ideas in a systematic way [9].

3) Action Learning Model. The researcher applied the concept of "Action Learning Model". Learn by talking with knowledgeable people and scholars e.g. District Agricultural Officers and farmers who have used the five-tier fish farming model for at least four years. Four stages are important: Problem Analysis and Problem Solving Action Planning and Implementation, Deciding on the next step, and Reflection and Evaluation.

4) Spiral Model. This relates to an innovative process of evaluation. Start with the objective of raising fish and aquatic animals, after actual tasks are performed, analyse your actions and performance. Learning from the Spiral Model involves a continuing process through multiple phases until a guideline, determining options and planning decisions is developed [8]. Finally, the evaluation itself has to be evaluated using Analytic Induction and Analysis by Typological Analysis.

\section{Content}

Farmers will be taught how to acquire knowledge about fish and other aquatic animals; more specifically observation techniques. How to observe tides, seasonal changes in natural water resources, various species of fish. This relates to the learning theory of constructivism, people learn from their experiences. People also obtain knowledge from previous generations, from experts in the matter, through field trips and training sessions. All these factors are important to build a foundation, which can be used to improve their lifestyle and to better manage their ponds.

Learning about fish in its natural habitat is a process of knowledge creation. Real natural phenomena can be empirically observed, true facts give empirical data. The meaning or translation of these data depends however on the individual, on the individual's way of thinking, his viewpoint and his previous experience. People get their information from various sources, sometimes second-hand, but they don't accept information uncritically. They process the raw data to form their own opinion. 


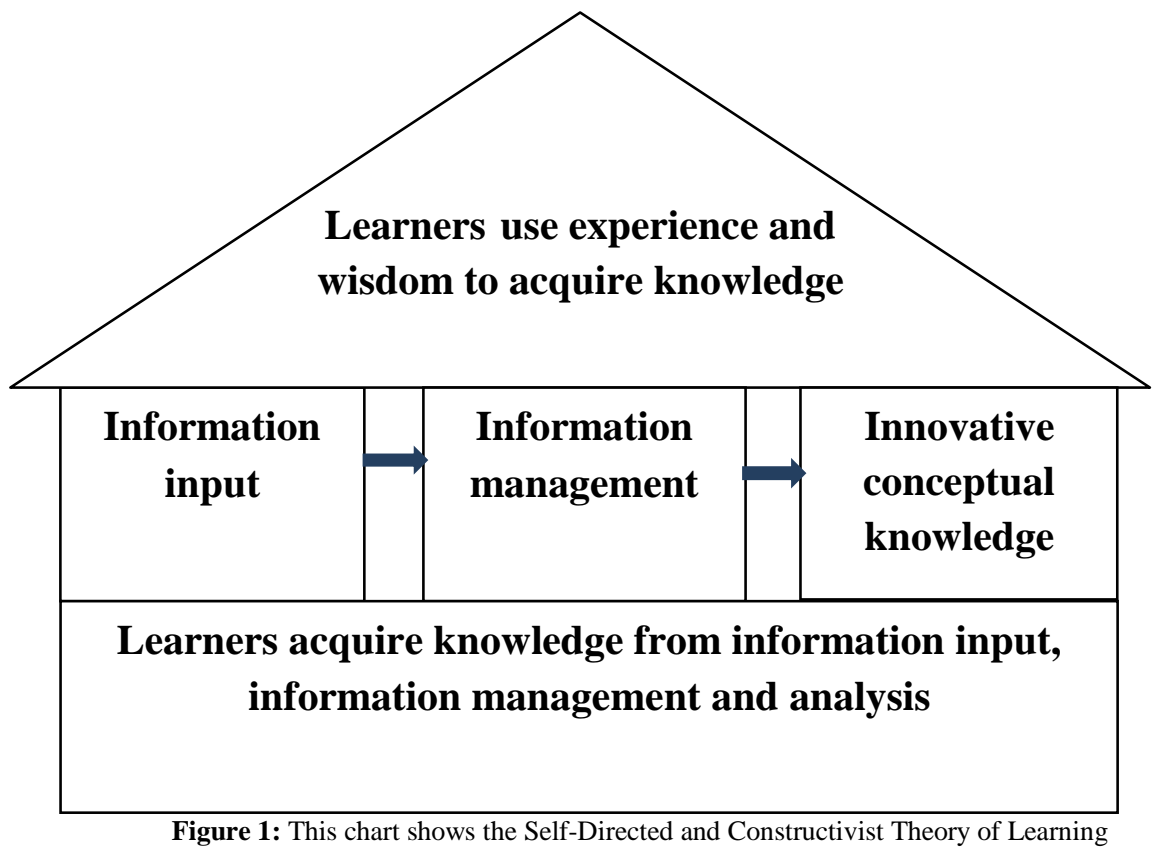

\section{Constructivist Theory of Learning}

The learner should have a passion for learning and a keenness to study and should be able tp understanding data systematically. He must understand the problems and obstacles he faces and envision the solution. As for the fish farmers, traditionally natural methods were used, but this research aims to show them a more developed and innovative way to solve their problems. We will do this by advising the farmers to put at least five different species of fish in the same pond, showing that this will lead to better results. Innovation is the key factor in developing a model of five-tier fish farming and aquaculture. Change in the cultural and social environment of the community is brought about by people who are willing to learn. They are natural leaders, who use their wisdom to develop the people in the community and solve its problems. This theory can be applied to create a good information management system (Thassana Khaemanee, 2005, page 94-96). Following we will explain how.

1. The Knowledge Creation Process. Acquiring knowledge is a process, which the learner goes through. People learn by doing, experiencing and witnessing events. From actual events the learner gets information. This information has to be analysed in order to be understood. The learner uses an individual system to manage the process, so he has access to knowledge and can reproduce it on his own.

2. Experimentation and Demonstration. Analysing and translating a variety of meanings by oneself will increase and develop a person's potential for learning. This way he can create his own knowledge. Experimentation and demonstration is a technique that makes the learner understand the processes that happen Demonstration and experimentation reveals multiple instances in multiple perspectives [6]. Participation in experiments can stimulate the learner to assess the knowledge by himself.

3. Emphasis should be on giving the farmer/ learner a direct role in the learning process in order to motivate him. Use activities to keep people alert and to stimulate them. Give the learner responsibility, from time to time change the roles of instructor and learner. Learners must be given the possibility to think for themselves. This will allow them to understand things completely and give rise to a self-centred learning.

4. Create a friendly atmosphere and follow moral principles. Ethics-based learning is respected and valued everywhere. Being sincere and honest will allow other stakeholders to trust and support you; this will affect the learning process in a beneficial way. Learners will have no doubts or issues and this in turn will make the learning process more effective.

5. Learners must play a significant role in the process. They should have the opportunity to express their own ideas. They should be able to change things that are relevant to the concept. They will learn from the results and consequences of their actions. 6. Educators should change their role to that of coaches. They should encourage their learners to use their own knowledge when necessary. This will create a sense of pride, which will aid them to retain that knowledge for a long time. It will also encourage them to continue learning. The instructor works as a facilitator and tries to release the power inside the learner. This will increase learners' motivation to innovate in order to get additional benefits.

7. Evaluation and assessment of the learning process. The evaluation process in this kind of learning should be flexible and use positive reinforcement. Assessment should also be creative, because this will encourage learners to use their own imagination and ideas. Don't set any specific targets, pay attention to what learners want and expect.

Creating knowledge of natural fish farming in this area is likely to happen because the region possesses natural canals spread across the area. The area is generally flat lowland and organic agriculture is practised. The village has a natural lifestyle, in harmony with the environment, the local climate, rainfall and quantity of available water. There is an abundance of fish and other aquatic animals in the area. We can study the natural occurring fish species to develop a system of five-tier fish farming based on natural conditions.

\section{Natural Fish Pond (Five-Tier Fish and Aquatic Animals)}

Local fish farmers found that natural water sources in the village and surrounding rice fields contain many fish and aquatic animals, which they don't have to feed. They observed the condition of the fish and other aquatic animals and learn about their behaviour and nature. Added to this, they have experience in traditional shrimp and fish farming. They use this previous experience to create a management plan for five-tier fish farming [2]. 


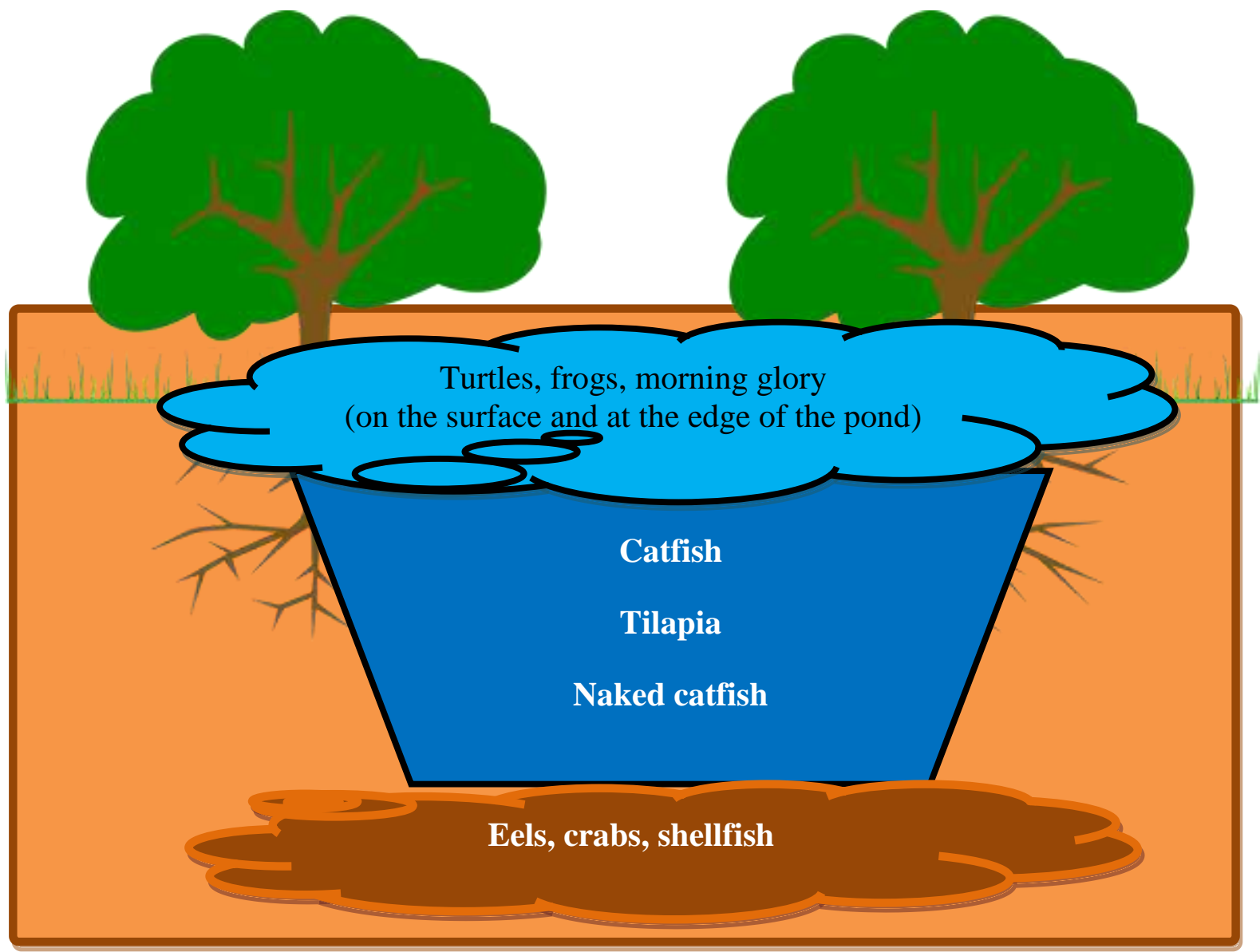

Figure 2: The illustration shows the five-tier fish model.

five-tier fish pond is a ditch or canal in marshland that is manmade, but it should resemble the natural occurring habitat of the aquatic fauna as closely as possible. Select fish species that can live together and are not aggressive towards each other. Mimic the natural water environment and resources. This is the basic guideline for managing five-tier fish farming.

Small fish ponds with a depth of 1-3 meters and a relatively small size (approximately $7 \times 12 \mathrm{~m}$ ) are considered ideal for this kind of aquaculture system. If the pond is deeper, it will be difficult to manage, especially during the rainy season. Farmers should put coconut fronds in the pond to give small shellfish something to attach themselves to. Simply pull out the fronds out of the water to harvest the shells. Feed the fish with rice bran, rice husks, coconut residue and other natural nutrients.

This model of fish farming uses a management system that resembles the natural environment as closely as possible. The fish is moved to the fishpond from natural ponds within the community. On the surface, water hyacinths, morning glory and duckweed are planted. The banks should have a gradual slope to make it look like a natural pond. The learning process and innovation development of family agriculture is comparable to the DMAIC-model, which imitates the Six Sigma system [16]. The DMAIC-model consists of the following five steps.

Step 1: D: Define. The first step is to define the procedure. For both plantations and five-tier aquaculture, farmers should try small-scale experiments first. If they encounter any problems, they should look for solutions in order to progress. This can be done by asking questions to people who have relevant experience: questions about the consequences of the problem and how to solve it.

Step 2: M: Measurement. What results can the farmer expect? What is the desired result? Then observe and measure the real data and compare them to what was expected. Analyse the obtained information and data and distinguish between facts and opinion
Step 3: A: Analysis. This is the step where farmers think about and analyse the issue at hand, causes and results. This is usually the stage where the fish farmers will come together and have a group discussion about their experience and the problems they face. Farmers agree on a system of analysis and exchange opinions.

Probable causes of the problem and possible links between them are analysed and discussed to determine the actual root problem. Farmers are encouraged to give comments. If after the initial discussion things are still unclear or any doubts exist, they can ask for advice from experienced people. The moment the problem and its cause are defined, the information should be shared with other people who face the same problem.

The next step is a check on the validity of the process. Recheck the process and the methods used to see if they contain any errors. Determine how the problem has an impact on the expected results. How can we solve this problem and avoid other unwanted effects that affect the results? To avoid the problem happening again or to find problems that are likely to occur, they can consult other experienced farmers, agricultural officers or scholars from the government or private sector.

Step 4: I: Improve. Follow the learning guideline that was obtained from consultation with experts and try it out in a small scale preliminary trial. Check to see the results and if necessary do it again with minor adaptations, e.g. change the way of feeding or adjust the water conditions as this may have an effect on the behaviour of the fish and other aquatic animals. Finally, evaluate the results, adjust your approach and expand to a larger scale.

Step 5: C: Control. This is about controlling the operation. It is a step towards confidence in the method. When the process is clearly established it will become an operational plan. Carry out the operation as planned. If a new problem arises, go through the cycle again, starting from the last observed relatively stable step. This way, new knowledge will be generated, which in turn will create innovation. 
As for fish farmers: try to learn from inherited wisdom, combined with direct experience obtained from observing and collecting data from real events and exposure to knowledge. Listen to advice and use all of this to analyse and check the issue yourself until you feel confident enough. This way of continuous learning will lead to new understanding and innovative management systems.

The five-tier aquaculture is based on a natural model and continuous learning is needed to understand new things. From previous experience, farmers can predict future problems. A willingness to understand the problem and find solutions by oneself and improve oneself along the way is what characterises the Self-Directed Learner. Inquisitiveness, wanting to find answers by oneself through experiments and a hands-on approach in order to prevent future problems will create this self-learning style.

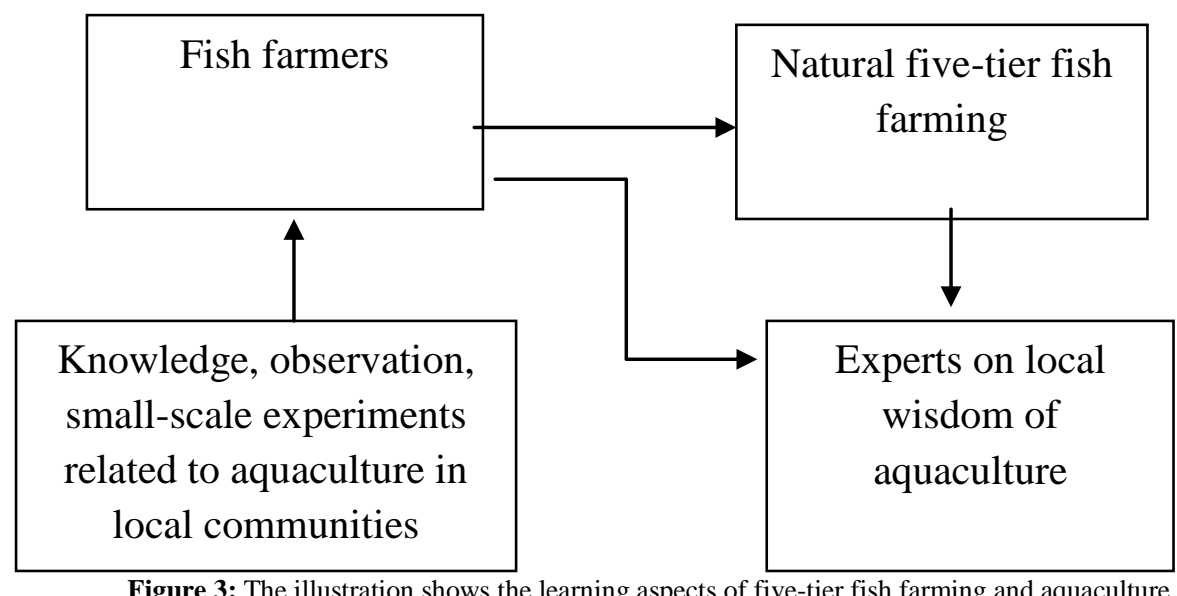

Figure 3: The illustration shows the learning aspects of five-tier fish farming and aquaculture.

The self-directed learner can be described as having a willingness to learn and to improve himself continuously through an exchange of knowledge. He should be guided and encouraged to frequently consult people, exchange information, discuss problems with knowledgeable people and conduct experiments. Theories need to be tested to lead to new knowledge that can be used as a guideline in planning a management system for aquaculture. Other factors that relate to the problem at hand have to be included so new techniques can be developed and improved, leading to a model that will solve or even prevent possible problems.

\section{Conclusion}

1) The learning process to manage five-tier fish farming and aquaculture was developed as an answer to internal pressure on communities. The need to overcome economic problems, which led to changes in career opportunities, family structure and social lifestyle, forced people to try and look for a new approach. Creating an innovative management system is a learning curve that needs support from the government to attend training sessions in the Sufficiency Economy and organic farming. In addition, local wisdom has to be rediscovered and people should be taught to think by themselves. This will form the foundation on which innovative development and improvement will be built.

The Self-Directed Learning process is the way to develop people to be effective learners. The learning trajectory should include adjusting activities to be in harmony with nature and organic farming. The main approach to develop and improve appropriate models that suit specific, local situations is through self-learning, planning, analysis and self-evaluation. Synthesised in a consistent Direct Learning format and combined with traditional local wisdom, this model will provide local communities with effective learners who will contribute to social progress. They will bring useful knowledge into the communities to develop an innovative, sustainable use of its resources.

2) This study is about developing an educational model for the management process to be used in five-tier fish farming and aquaculture. Farmers who would like to follow the model should learn about traditional local wisdom from previous generations and learn by observing, testing and experimenting with various species of fish and types of ponds. Use different forms of assessment, evaluation, analysis and knowledge; repeat your experiment if necessary and check your results with experts. Selfassessment and experimental validation are used as a guideline to innovative development in this style of fish farming. Farmers can then become experts on local aquatic knowledge themselves and direct development in their community as trusted leaders.

\section{Suggestions}

This study about the learning process to develop knowledge about five-tier fish farming was aimed at creating a guideline for individual learning (Self-Directed) and at producing local experts on aquaculture. A habit of self-learning and a culture of enjoying learning should be created. In addition, people should be encouraged to use critical thinking, experiments, observation, verification of results and analysis to arrive at a knowledge base that is useful in managing the community resources.

1. Community leaders (specifically village level officers) should encourage people and give them the opportunity to learn to become experts on local wisdom in various areas. Observe how various kinds of stimuli work; conduct experiments, observe, evaluate and analyse to develop a systematic management system within the context of the community that can be used by individuals and social groups.

2. The main policy of the government and private sector should be to give support, financially and otherwise, to individuals and groups in the community to gain knowledge and wisdom. This knowledge, in turn, can be used to further develop techniques and innovative methodology. Results observed in the community, on a local level, can then be expanded to a larger, regional level.

\section{References}

[1] Ann R. J. Briggs, Marianne Coleman and Marlene Morrison. (2012) Research Methods in Educational, Leadership and Management. California: SAGE publication Inc.

[2] David G. Myers (2005) Social Psychology. New York : Mc Graw Hill.

[3] Ellen Berscheid and Pamela Regan (2005) The Psychology of Interpersonal Relationships New York: Pearson.

[4] Gillian Symon and Catherine Cassell. (2012). Qualitative Organizational Research Core Methods and Current Challenges. California : Sage Publications Inc. 
[5] Gordon Rugg and Marian Petre. (2007). A Gentle Guide To Research Methods. New York: Mc Graw Hill.

[6] Kolb, D.K. (1984). Experiential Learning : Experience as the Source of Learning and evelopment. New Jersey : Prentice-Hall Inc.

[7] Luis R Gomez-Mejia and David B. Balkin (2012) Management People Performance Change. New York: Pearson.

[8] Lunjakon Nillakan. (2014). Learning Styles Development. Nagabut Journal Review, Nakhon Si Thammarat: Nakhon Si Thammarat Rajabhat University, Vol 6, No 2 July-December 2014, P.90-98. (in Thai).

[9] Orawan Sae-nga, Harchai Sitharak, and Lanjakorn Nilkarnjana.(2016). To take a lesson bio-diesel production from old oil. Nagabut Journal Review, Nakhon Si Thammarat: Nakhon Si Thammarat Rajabhat University, Vol 8, No 1 January-June 2016 , P.117-126. (in Thai).

[10] Paul D. Leedy and Jeanne Ellis Ormrod (2015) Practical Research Planning and Design. New York: Pearson.

[11] Pricha Samakkhi and Punya Lertgrai. (2014). Observation Technique for Research and Development. Nagabut Journal Review, Nakhon Si Thammarat: Nakhon Si Thammarat Rajabhat University, Vol 6, No 1 January-June 2014, P.58-66. (in Thai).

[12] Punya Lertgrai. (2009). Innovation of oil palm plantation : Pak Phanang Basin Nakhon Si Thammarat. Thesis, Doctor of Philosophy (Education for Locality Development). Nakhon Si Thammarat Rajabhat University, Nakhon Si Thammarat. (in Thai)

[13] Punya Lertgrai. and Lunjakon Nillakan. (2016). Fieldwork and data collection in local communities. Nagabut Journal Review, Nakhon Si Thammarat: Nakhon Si Thammarat Rajabhat University, Vol 8, No 2 July-December 2016, P.1-10. (in Thai)

[14] Sayan Panbuth. (2014). Development Knowledge to Develop an Integrated Agricultural Business of Ban Bang Yai Community Enterprises, Moo 4, Bang Nai Se Sub-District, Takuapa District,PhangNga Province. Nagabut Journal Review, Nakhon Si Thammarat: Nakhon Si Thammarat Rajabhat University, Vol 6, No 1 January-June 2014, P.48-57. (in Thai).

[15] The Community Development Department. (2006). Innovative Solution to Volume 1: Knowledge Management for Developers. Bangkok: The Community Development Department, Ministry of Interior. (in Thai).

[16] Werayut Chatakan. (2009). Management Techniques of Professional Education Executive Bangkok: chulalongkorn university Press. (in Thai). 